\title{
Cetacean conservation planning in a global diversity hotspot: dealing with uncertainty and data deficiencies
}

\author{
Fabrice Stephenson (D) $1, \uparrow$ Judi E. Hewitt, ${ }^{1,2}$ Leigh G. Torres, ${ }^{3}$ Théophile L. Mouton, ${ }^{4}$ Tom Brough, ${ }^{1}$ \\ Kimberly T. Goetz, ${ }^{5,6}$ Carolyn J. Lundeuist, ${ }^{1,7}$ Alison B. MacDiarmid, ${ }^{6}$ \\ JoAnNe Ellis, ${ }^{8}$ and Rochelle CONSTANTINE ${ }^{7,9}$ \\ ${ }^{1}$ National Institute of Water and Atmosphere (NIWA), Hamilton, New Zealand \\ ${ }^{2}$ Department of Statistics, University of Auckland, Auckland, New Zealand \\ ${ }^{3}$ Department of Fisheries and Wildlife, Marine Mammal Institute, Oregon State University, Newport, Oregon, USA \\ ${ }^{4}$ Marine Biodiversity, Exploitation, and Conservation (MARBEC), UMR IRD-CNRS-UM-IFREMER 9190, Université de Montpellier, \\ Montpellier 34095 France \\ ${ }^{5}$ National Oceanic and Atmospheric Administration, National Marine Fisheries Service, Marine Mammal Laboratory, Alaska Fisheries \\ Science Center, Seattle, Alaska, USA \\ ${ }^{6}$ National Institute of Water and Atmosphere (NIWA), Wellington, New Zealand \\ ${ }^{7}$ Institute of Marine Science, University of Auckland, Auckland, New Zealand \\ ${ }^{8}$ School of Science, University of Waikato, Tauranga, New Zealand \\ ${ }^{9}$ School of Biological Sciences, University of Auckland, Auckland, New Zealand
}

Citation: Stephenson, F., J. E. Hewitt, L. G. Torres, T. L. Mouton, T. Brough, K. T. Goetz, C. J. Lundquist, A. B. MacDiarmid, J. Ellis, and R. Constantine. 2021. Cetacean conservation planning in a global diversity hotspot: dealing with uncertainty and data deficiencies. Ecosphere 12(7):e03633. 10.1002/ecs2.3633

\begin{abstract}
Many cetacean species are at risk from anthropogenic disturbances including climate change, pollution, and habitat degradation. Identifying cetacean hotspots for conservation management is therefore required. Aotearoa-New Zealand waters are used by 53\% of the world's cetacean species and are a global cetacean diversity hotspot. Using geographic predictions of cetacean taxa, we aimed to identify important areas within New Zealand waters using two methods: estimates of cetacean richness and a spatial prioritization analysis. For both methods, we investigated how varying levels of uncertainty in predictions of the taxa' occurrence layers would affect our interpretation of cetacean hotspots. Despite some marked spatial differences in distribution of important areas for cetacean diversity, both methods, across all uncertainty scenarios, highlighted six distinct deep offshore regions as important habitat. Generally, inshore areas had lower richness estimates than offshore areas, but these remain important for conservation for species with limited ranges (e.g., the endemic Māui and Hector's dolphins), and in some places had similar richness values to offshore hotspots. Furthermore, inshore hotspots had lower uncertainty in predicted taxa distribution and richness estimates. The use of two different uncertainty estimates allows the integration of distributional information from differing sources (different modeling methods with varying numbers of cetacean records) to be integrated in a robust and conservative way. Identification of cetacean hotspots with varying levels of uncertainty provides a robust and efficient step toward prioritizing areas for conservation management in a participatory process.
\end{abstract}

Key words: New Zealand; richness; spatial prioritization; species distribution models; uncertainty.

Received 13 July 2020; revised 14 January 2021; accepted 2 February 2021; final version received 29 April 2021. Corresponding Editor: Sean P. Powers.

Copyright: () 2021 The Authors. This is an open access article under the terms of the Creative Commons Attribution License, which permits use, distribution and reproduction in any medium, provided the original work is properly cited.

$\dagger$ E-mail: Fabrice.Stephenson@niwa.co.nz 


\section{INTRODUCTION}

Marine mammals play key roles in the world's ecosystems and are important to people through economic and social benefits from related tourism, culture, and recreation (Schipper et al. 2008, Hammerschlag et al. 2019). Despite their importance, there remains a paucity of information for a number of marine mammal taxa due to their elusive behavior and offshore habitat use. However, it is well established that many populations are at risk from anthropogenic disturbances through habitat degradation, including climate change, pollution, underwater noise, and fisheries competition, and direct hunting (Schipper et al. 2008, Albouy et al. 2017, Ramírez et al. 2017, Clapham and Baker 2018, Reeves 2018, Hammerschlag et al. 2019, Albouy et al. 2020). Broad global-scale estimates of cetacean distribution and richness have been developed (Kaschner et al. 2006, 2011) providing crucial information for assessing potential large-scale effects of anthropogenic impacts on different populations and taxa (e.g., Pershing and Stamieszkin 2020). For example, Albouy et al. (2017) identified global multifaceted biodiversity hotspots (based on functional diversity, phylogenetic diversity, and species richness) for marine mammals and their potential spatial overlap with human threats. More recently, Albouy et al. (2020) used a trait-based approach to assess the vulnerability of all marine mammals to global warming. The latter work demonstrated that potential extinctions of marine mammals that were most at risk from global warming could induce a disproportionate loss of functional diversity in marine ecosystems. There are welldocumented shifts in the spatiotemporal distribution of cetaceans (e.g., Friday et al. 2013, Ramp et al. 2015, Meyer-Gutbrod and Greene 2018), pinnipeds (Szpak et al. 2018, e.g., Hückstädt et al. 2020), and polar bears (Ursus maritimus; e.g., Laidre et al. 2020) due to climate changeinduced ecosystem shifts. In addition, several other studies have documented the impact of localized anthropogenic activities on marine mammals, such as underwater noise, pollution, ship strikes, and over-harvesting of prey species (Davidson et al. 2012, Jepson et al. 2016, Azzellino et al. 2017, Scales et al. 2017, Abrahms et al. 2019).

ECOSPHERE *www.esajournals.org
Global-scale conservation practices are widely acknowledged as having positive effects on biodiversity (Hoffmann et al. 2010, Costello 2019, Purvis et al. 2019); however, regional (national) conservation efforts may be equally important, given current challenges for transboundary conservation efforts (Mason et al. 2020) and for highly mobile species (Woinarski et al. 1992). Conservation efforts in New Zealand may be particularly important because it is recognized as a globally important cetacean diversity hotspot (Myers et al. 2000, Davidson et al. 2012, Albouy et al. 2017). In total, 53\% $(n=47)$ of the world's known cetacean species, subspecies, and/or ecotypes including resident, migrant, or vagrant taxa have been identified in the New Zealand Exclusive Economic Zone (EEZ; Baker et al. 2019). Seven of these, including the endemic Hector's (Cephalorhynchus hectori hectori) and Māui dolphins (C. h. maui), are listed as Endangered or Critically Endangered under the IUCN threat classification system (IUCN 2001), and 28 are considered Data Deficient, hence are unable to be classified (IUCN 2015). All cetacean species in New Zealand's marine environment are protected under national law by the New Zealand Marine Mammals Protection Act (1978). Recent species distribution models (SDMs) developed by Stephenson et al. (2020b) produced a comprehensive understanding of cetacean distribution in New Zealand for 30 species, subspecies, and species complexes. Such work can inform the management of potential threats to cetaceans such as fishing, shipping, mineral extraction, and other threats that are heterogenous in space (Baker et al. 2019). However, questions remain as how to best use this information for management given differing levels of uncertainty and the implications of ignoring species that are either rare or for which little information exists. To date, we are not aware of any studies that have attempted to identify hotspots of cetacean diversity within the New Zealand EEZ. This lack of information is a major limitation with respect to the effective conservation of New Zealand's biodiversity, including highly migratory species crossing jurisdictional waters, facing intensifying anthropogenic threats.

The most commonly used approach to identify areas of conservation priority is the biodiversity hotspot approach. This approach was originally 
used by Myers (1988) to identify areas facing exceptional degrees of threat and supporting exceptional concentrations of species with high levels of endemism (Myers et al. 2000). A commonly used approach to identify biodiversity hotspots is to estimate species richness. However, distribution of species richness may be biased toward areas where species with large overlapping ranges occur; that is, those species with restricted non-overlapping ranges will not contribute greatly toward the summed species richness (Veach et al. 2017). Furthermore, areas with high richness may represent marginal habitats for several species but may not represent ideal habitats (i.e., those habitats likely to support healthy populations) for any of these taxa.

Spatial prioritization analyses that account for range size bias can also be used for identifying biodiversity hotspots (e.g., Hillman et al. 2020). Both richness estimates and spatial prioritization analyses require knowledge of the geographical distributions of target species. SDMs offer a recognized correlative method of predicting species' probability of occurrence (Guisan and Thuiller 2005, Elith et al. 2006). Information on the presence of species, such as from incidental sightings, is used as an input response variable to model a species' ecological niche based on the assumption that the distribution of known encounters reflects the species' environmental preferences. The performance of SDMs is, however, highly dependent on sample size and sampling extent (Stockwell and Peterson 2002, Wisz et al. 2008, Bean et al. 2012). Hence, rare species may be highly challenging to incorporate into SDM analyses (Granger et al. 2015, Ferrer-Sánchez and RodríguezEstrella 2016), possibly introducing bias in the designation of areas of high importance for the conservation of biodiversity and ecosystem functions (Mouillot et al. 2013, Ferrer-Sánchez and Rodríguez-Estrella 2016). In addition to a lack of distributional data for rare taxa, the uncertainty in distribution data and/or accounting for data availability is rarely considered for conservation planning (Moilanen et al. 2006b, Rowden et al. 2019). Given that many of the cetacean species occurring in New Zealand are data deficient or inhabit poorly surveyed offshore waters with very few observation records, it is important to not only consider these species but also consider the uncertainty surrounding their distributions.
Furthermore, understanding the effects of using several, differing, measures of uncertainty for spatial management is crucial for impact assessment of marine activities and conservation efforts (Beale and Lennon 2012), as well as for highlighting potential data gaps.

Here, we seek to identify cetacean diversity hotspots in a globally important location for cetaceans, the New Zealand EEZ. Despite some criticisms (Marchese 2015, Veach et al. 2017), models of species richness and the concept of diversity hotspots are widely used to develop costeffective strategies for biodiversity conservation (Myers et al. 2000, Norman 2003, Orme et al. 2005). Using mean long-term geographic predictions of species' occurrences (at a 1-km grid resolution, annual scale) from Stephenson et al. (2020a), we aim to identify important areas within the New Zealand EEZ for cetacean taxa using two methods: estimates of cetacean richness and a spatial prioritization analysis. For both methods, we investigate how varying levels of uncertainty in spatial predictions of occurrence influence the interpretation of cetacean hotspots and their efficacy for informing national and global conservation efforts.

\section{Methods}

\section{Study area}

The study area extends over 4.2 million $\mathrm{km}^{2}$ of the South Pacific Ocean within the New Zealand EEZ ( $25-57^{\circ}$ S; $162^{\circ}$ E to $172^{\circ} \mathrm{W}$; Fig. 1$)$. New Zealand's two long and narrow main islands span a wide latitudinal range, resulting in a diverse array of environmental conditions within the waters of the EEZ (Bradford-Grieve et al. 2006, Stephenson et al. 2018).

\section{Distribution models of cetacean taxa}

At-sea cetacean sighting records of 30 cetacean species, subspecies, and species complexes (herein referred to as cetacean taxa), collected over the period 1980-2017, were collated from multiple databases (Stephenson et al. 2020a). Depending on the number of records available for each taxa, different analyses were undertaken to estimate distributions (Table 1). For those taxa with fewer than 50 recorded sightings, relative environmental suitability (RES) models (Kaschner et al. 2006) were used to predict probability 


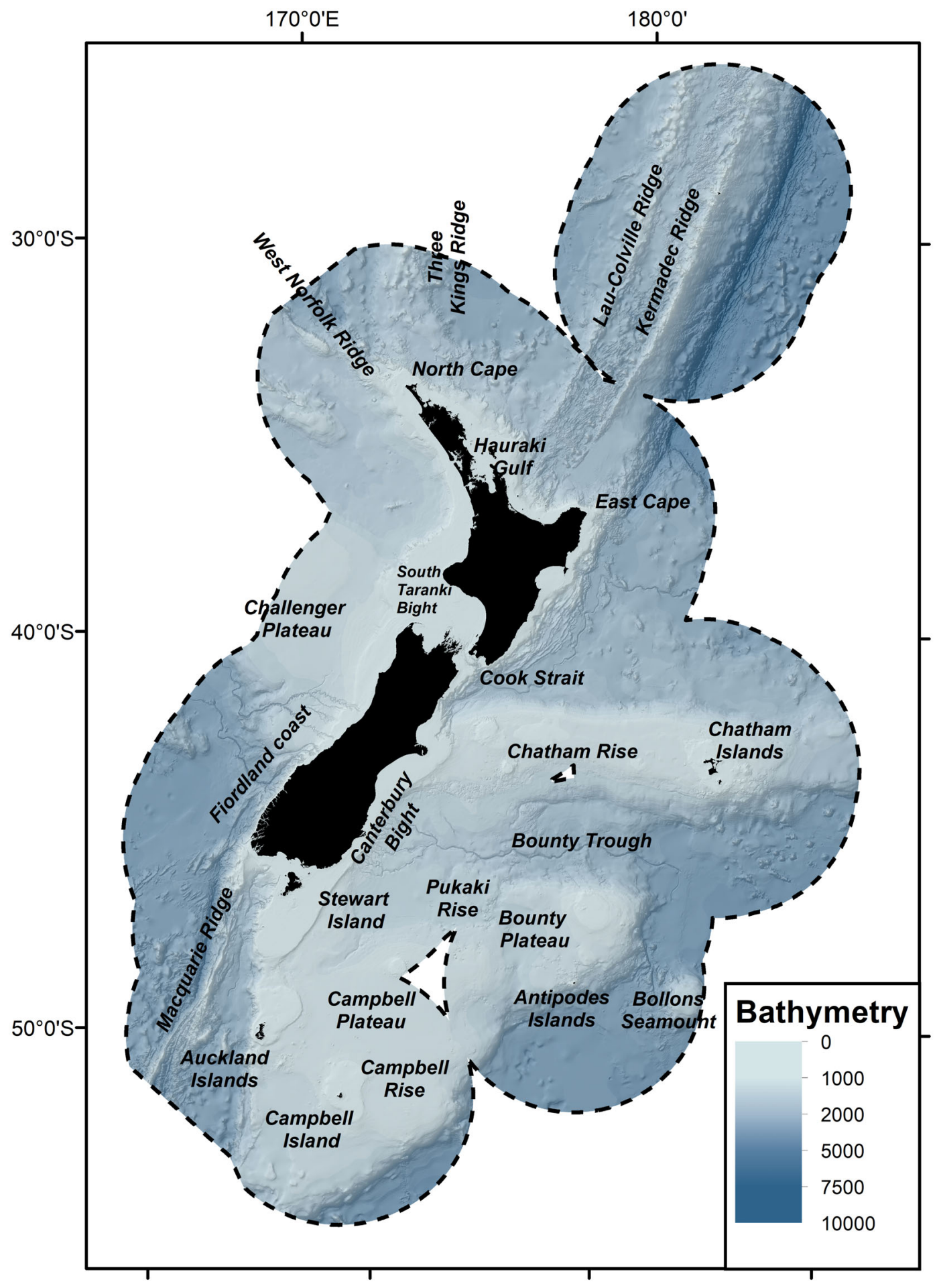

Fig. 1. Map of the study region (New Zealand Exclusive Economic Zone [EEZ], black dashed line), bathymetry, and feature names used throughout the text; figure modified from Stephenson et al. (2020a). 
Table 1. Number of cetacean sighting records per species, subspecies, or species complexes included in Stephenson et al. (2020a).

\begin{tabular}{|c|c|c|c|}
\hline Taxa common names & Species/subspecies & No. of sighting records & $\begin{array}{c}\text { AUC calculated from } \\
\text { evaluation data }\end{array}$ \\
\hline Common dolphin & Delphinus delphis & 4411 & $0.90 \pm 0.01$ \\
\hline Māui dolphin & Cephalorhynchus hectori maui & 1051 & $0.99 \pm 0.00$ \\
\hline Hector's dolphin & C. h. hectori & 3688 & $0.99 \pm 0.00$ \\
\hline Dusky dolphin & Lagenorhynchus obscurus & 823 & $0.95 \pm 0.01$ \\
\hline Pilot whale (2 spp.) & $\begin{array}{l}\text { Globicephala melas } \\
\text { G. macrorhynchus }\end{array}$ & 680 & $0.91 \pm 0.02$ \\
\hline Humpback whale & Megaptera novaeangliae & 629 & $0.85 \pm 0.02$ \\
\hline Bryde's whale & Balaenoptera edeni brydei & 593 & $0.93 \pm 0.01$ \\
\hline Killer whale & Orcinus orca & 569 & $0.79 \pm 0.02$ \\
\hline Bottlenose dolphin & Tursiops truncatus & 498 & $0.81 \pm 0.02$ \\
\hline Sperm whale & Physeter macrocephalus & 497 & $0.92 \pm 0.01$ \\
\hline Southern right whale & Eubalaena australis & 477 & $0.94 \pm 0.01$ \\
\hline Blue whale (2 recognized sub spp.) & $\begin{array}{c}\text { Balaenoptera musculus musculus } \\
\text { B. m. brevicauda }\end{array}$ & 355 & $0.95 \pm 0.02$ \\
\hline Sei whale & Balaenoptera borealis & 70 & 0.81 \\
\hline Fin whale & Balaenoptera physalus & 61 & 0.79 \\
\hline Minke whale & Balaenoptera acutorostrata & 57 & 0.81 \\
\hline Arnoux's beaked whale & Berardius arnuxii & 31 & na \\
\hline False killer whale & Pseudorca crassidens & 28 & na \\
\hline Southern right whale dolphin & Lissodelphis peronii & 27 & na \\
\hline Gray's beaked whale & Mesoplodon grayi & 9 & na \\
\hline Cuvier's beaked whale & Ziphius cavirostris & 7 & na \\
\hline Risso's dolphin & Grampus griseus & 5 & na \\
\hline Shepherd's beaked whale & Tasmacetus shepherdi & 5 & na \\
\hline Southern bottlenose whale & Hyperoodon planifrons & 4 & na \\
\hline Andrew's beaked whale & Mesoplodon bowdoini & 2 & na \\
\hline Hourglass dolphin & Lagenorhynchus cruciger & 2 & na \\
\hline Pygmy sperm whale & Kogia breviceps & 2 & na \\
\hline Blainville's beaked whale & Mesoplodon densirostris & 1 & na \\
\hline Dwarf minke whale & Balaenoptera acutorostrata & 1 & na \\
\hline
\end{tabular}

Notes: Taxon names in boldface indicate taxa for which boosted regression tree probability of occurrence models was fitted; roman text indicates taxa for which relative environmental suitability models were run. AUC values were calculated using evaluation data and for those models that were bootstrapped are shown as the mean \pm SD.

of occurrence (Table 1). Briefly, RES models predict the geographical ranges of taxa using basic descriptive, widely available data (i.e., the relationships between taxa and three environmental variables: sea surface temperature, water depth, and distance to shore) that are available for most taxa, including those for which few (or no) recorded locations are available (Kaschner et al. 2006). Although RES is a conceptually simple modeling approach, it is a well-established method that has been successfully applied to predict global distributions of cetaceans and other marine taxa (Kesner-Reyes et al. 2016). Stephenson et al. (2020a) concluded that estimated probability distributions using RES were consistent with the limited sighting records available for 15 rarely sighted taxa, providing some evidence that the environmental niche of an individual taxa was at least encompassed within the RES prediction. RES predictions are currently the best available information for rare taxa; however, given the low levels of information, these predictions should be used cautiously (Stephenson et al. 2020a).

For taxa with more than 50 recorded sightings (bold typeface in Table 1), boosted regression tree (BRT) models (Elith et al. 2006) were fitted using 14 gridded environmental variables $(1-\mathrm{km}$ grid resolution, annual scale), bootstrapped 100 times, to predict probability of occurrence and a 
spatially explicit measure of uncertainty (measured as the standard deviation of the mean [SD]; Stephenson et al. 2020b). BRT models used to predict cetacean taxon occurrence performed well (model goodness of fit: AUC $>0.75$; Table 1). Distributions of individual taxon occurrence aligned with information on known distributions of some taxa and were visually congruent with recorded sighting data (used to train the models) and evaluation data. A separate independent statistical validation of models for a subset of taxa (bottlenose [Tursiops truncates], common [Delphinus delphis], Hector's and dusky dolphins [Lagenorhynchus obscurus], and Bryde's [Balaenoptera edeni brydei] and killer whales [Orcinus orca]) provided further evidence that these model predictions were robust. See Stephenson et al. (2020a) for further details on methodology, description of environmental predictors, model parametrization, and results.

\section{Spatially explicit measures of uncertainty}

Two measures of spatially explicit uncertainty were produced by Stephenson et al. (2020a): an estimate of the coverage of the environmental space by all cetacean sighting records (herein referred to as environmental coverage; Appendix S1: Fig. S1A), and estimates of the uncertainty of the distributions for those taxa with sufficient data (herein referred to as taxa uncertainty, example shown in Appendix S1: Fig. S1B). All maps of taxa distributions and associated estimates of spatially explicit uncertainty are available in Stephenson et al. (2020a).

When model predictions are projected into areas for which no occurrence data exist, it is important to understand the similarity between the new environments and those used in training the model (Elith et al. 2010). The environmental coverage (Smith et al. 2013, Stephenson et al. $2020 a$ ) provides an indication of which parts of this environmental space contain many sighting records (across all taxa) and are presumed to have more certain predictions of taxa distributions. Similarly, parts of the environmental space containing few sighting records are identified with the assumption that the relationship between the environment and the sighting records is poorly understood and predictions are less certain (Smith et al. 2013). Methods and the mapped coverage of the environmental space are provided in Appendix S1.

Associated uncertainty estimates of taxon distributions were provided as standard deviation (SD) of the mean predicted probability of occurrence (estimated through bootstrapping of the BRT models, described in section Cetacean systematic conservation planning). An important consideration for these uncertainty layers is that the BRT model predictions are not well extrapolated into unsampled environmental space (i.e., the predicted values shown will simply be those of the closest environmental space). In addition, the confidence estimates may remain low in poorly sampled areas because the bootstrapping requires variability between samples to produce estimates of error.

\section{Cetacean richness hotspots}

Two methods were used to identify important areas for multiple cetacean taxa: (1) distribution of cetacean richness; and (2) spatial prioritization analyses. For both methods, we investigated how varying levels of uncertainty in the spatial layers affect interpretation of cetacean hotspots (Fig. 2). Here, we present results of three uncertainty scenarios for both the cetacean richness and spatial prioritization analyses: (1) no inclusion of uncertainty estimates (herein referred to as the "baseline" scenario); inclusion of moderately weighted uncertainty estimates (herein referred to as "moderate-uncertainty" scenarios); and the inclusion of highly weighted uncertainty estimates (herein referred to as "high-uncertainty" scenarios; Fig. 2).

\section{Cetacean richness}

Cetacean richness for the baseline scenario (without inclusion of uncertainty) was estimated by summing the occurrence probability predictions from individual modeled taxon distributions (Fig. 2; Ferrier and Guisan 2006, Calabrese et al. 2014, Stephenson et al. 2020b).

Cetacean richness for moderate- and highuncertainty scenarios was produced by downweighting the individual taxon occurrence layers prior to summing (Fig. 2). Down-weighting for taxon occurrence layers predicted using BRTs was done by multiplying individual taxon distribution layers by their associated cross-validation AUC scores (Table 1). Uncertainty discounting 


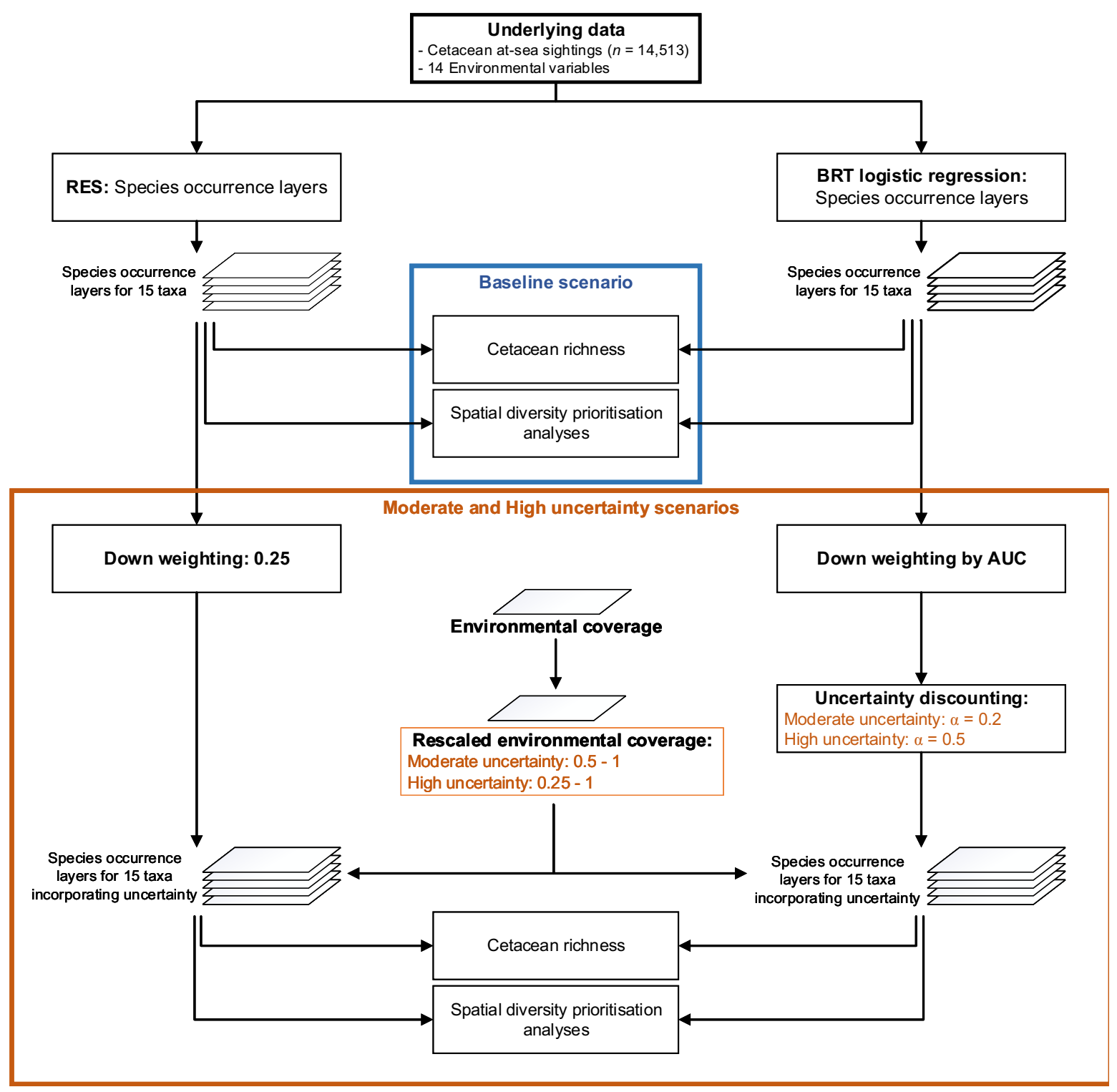

Fig. 2. Infographic depicting key steps in the preparation of spatial data layers and their use for estimating cetacean richness and spatial prioritization analyses with varying levels of incorporation of uncertainty (baseline, moderate-uncertainty, and high-uncertainty scenarios).

was then applied to these layers using methods described in Moilanen et al. (2006a), where infogap theory is applied to achieve conservation targets given the most adverse choice of probabilities (in other words, when all probabilities are at their lower bounds). For all taxon layers, this was implemented following Eq. 1 (described in Moilanen et al. 2006a):

$$
P_{i j}=P_{i j}-\alpha W_{i j}
$$

where $\alpha$ is the degree of uncertainty, and $W_{i j}$ is any error measure (here, the SD of each cell from the spatially explicit uncertainty maps) related to the accuracy of $P^{*}{ }_{i j}$ (the mean probability of occurrence for cetacean taxa $j$ in cell $I$; Moilanen and Wintle 2006). A range of $\alpha$ values were 
trialed: $0.1,0.2,0.3,0.4$, and 0.5 . Results using a moderate $(\alpha=0.2)$ - and a high-uncertainty weighting ( $\alpha=0.5)$ were subsequently used in the moderate-uncertainty and high-uncertainty scenarios, respectively.

Since model evaluation metrics and spatially explicit estimates of uncertainty are not available when using RES models, RES layers were subjectively down-weighted using a 0.25 multiplier. This value was arbitrary but reflects expert evaluation of the relative value of RES values compared with BRT models.

Finally, the environmental coverage was used to down-weight both RES- and BRT-derived taxon distribution layers. The environmental coverage layer was rescaled so that values ranged from 0.5 to 1 and 0.25 to 1 for the moderateuncertainty and high-uncertainty, scenarios, respectively. The rescaled environmental coverage layer was multiplied with the taxon distribution layers, resulting in areas with high environmental coverage retaining their predicted occurrence values, whereas less certain areas with lower environmental coverage were downweighted. The rescaling of environmental coverage ensured that many offshore areas were retained yet reflect that these areas are poorly understood (but still provide some useful information). The adjusted RES- and BRT-derived taxon distribution layers were summed to produce a single conservative estimate of richness for the study area (Fig. 2).

\section{Spatial diversity prioritization}

A spatial diversity prioritization analysis, using the software Zonation (Moilanen et al. 2009), was undertaken to identify a representative set of areas with the highest conservation value for cetacean taxa in New Zealand (incorporating the importance of range-restricted species that do not contribute greatly to summed estimates of richness). Zonation initially assumes that the entire area of interest (study area) is protected, sequentially removing in a stepwise fashion those cells making the lowest contribution to the representation of a full range of biodiversity features, in this case, cetacean distribution layers (Moilanen et al. 2014). For all analyses presented here, the additive benefit function (ABF) algorithm was used for prioritization (Moilanen 2007). This method generally gives greater value to areas with overlapping distributions of species (Moilanen 2007, Virtanen et al. 2018).

Spatial prioritization analysis for the baseline scenario (without inclusion of uncertainty) was undertaken with all layers equally weighted and no estimates of uncertainty (Fig. 2). Default settings were used for other parametrization options (e.g., edge removal, no aggregation algorithm, no cost layers, and no administrative unit analysis).

Spatial prioritization analysis for moderateand high-uncertainty scenarios was produced by down-weighting the individual taxon occurrence layers based on confidence in model predictions, the individual taxon uncertainty layer (if available), and the environmental coverage prior to analysis (Fig. 2). As for richness estimates for moderate- and high-uncertainty scenarios, BRT taxon distribution layers were down-weighted according to their cross-validation AUC scores and their respective spatially explicit uncertainty layer with a weighting of $\alpha=0.2$ and $\alpha=0.5$. RES taxon occurrence layers were downweighted (layer weighting: 0.25). Finally, the rescaled environmental coverage (ranging from 0.5 to 1.0 and 0.25 to 1.0 for the moderateuncertainty and high-uncertainty scenarios, respectively) was again used to down-weight all taxon distribution layers using the condition function in Zonation (which implements the same down-weighting as that described for the richness estimates). Default settings were used for other parametrization options.

Zonation outputs included a single map of biodiversity prioritization, with areas identified from the highest to lowest priority in terms of conservation value (Moilanen et al. 2011). In this study, outputs were presented as maps that identified the top $5 \%, 10 \%, 20 \%$, and $30 \%$ priority areas for cetacean diversity. Other Zonation outputs included the proportion of each taxon's (assumed) range protected across the range of prioritization (i.e., $0-100 \%$ of total area selected collated into tables). At each priority conservation level (top 5\%,10\%, etc.), the ranges of individual taxa contained within these areas can be examined providing information on whether taxa are adequately represented. Prioritizations can then be judged according to whether a greater proportion of the taxon's range is protected than the proportion of the priority area 
(e.g., if taxon $X$ has $\geq 5 \%$ of its range protected within the top $5 \%$ priority areas, this would be considered an adequate solution for taxon X). It should be noted that the proportion of each taxon's range will tend to decrease (reduced in spatial extent) with increasing uncertainty because the taxon's occurrence values have been downweighted to the point of removal for some cells resulting in a smaller total (assumed) range. Comparison between uncertainty scenarios was nevertheless considered because erroneous areas (most likely those areas with higher uncertainty) would not be included.

\section{RESULTS}

\section{Cetacean richness}

Cetacean richness estimates for the baseline scenario ranged from 1 to 8 inshore $(<50 \mathrm{~km}$ from the coast) and 9 to 18 for offshore areas (Fig. 3A). Unsurprisingly, the highest richness estimates were lower (maximum: 18, Fig. 3A) than the 30 taxa modeled since not all taxon distributions overlapped. The highest estimates were observed in deep offshore waters $(>50 \mathrm{~km}$ from the coast) along the southern part of the Lau-Colville and Kermadec Ridges (see Fig. 1 for place names, Fig. 3A, iii), Macquarie Ridge and along the western edge of the Campbell Plateau (Fig. 3, ii), and the northern and western edges of the Bounty Trough and the north and south of the Chatham Rise (Fig. 3A, iv). Much of the high richness offshore areas had lower confidence (as measured by the coverage of the environmental space-crisscross black lines in Fig. 3A). Closer to shore $(<50 \mathrm{~km})$, cetacean richness was generally predicted to be lower (predominately between 3 and 4), although the Fiordland coast, North Cape, South Taranaki Bight, Kaikōura Coast, Cook Strait, and eastern Bay of Plenty all had regions of moderate cetacean richness (richness 5-8; Fig. 3A).

There were clear differences in predicted cetacean richness with the inclusion of uncertainty compared with the baseline scenario, although broad patterns in richness hotpots were similar (moderate- and high-uncertainty scenarios; Fig. 3 $\mathrm{B}, \mathrm{C}$, respectively). Maximum predicted richness was 9 in the high-uncertainty scenario (Fig. 3C) compared with 11 in the moderate-uncertainty scenario (Fig. 3B) and 18 in the baseline scenario
(Fig. 3A). With increasing weighting of uncertainty, vast areas offshore displayed lower richness (Fig. 3B, C). However, there was greater contrast between areas with low and high estimated richness in these maps that incorporated uncertainty; that is, many hotspots of cetacean richness remained the same but were more easily observed (e.g., compare Fig. 3A, B, C, iii, ii, iv). The higher weighting of uncertainty further highlighted areas closer to shore as important regions, which had only moderate-richness values in the baseline scenario, including North Cape (Fig. 3B, C, i), Kermadec Islands (Fig. 3B, C, ii), East Cape, South Taranaki Bight (Fig. 3B, $\mathrm{C})$, and the west coasts of South Island and North Island (Fig. 3B, C, i). Some offshore areas with low environmental coverage (crisscross black lines in Fig. 3) still displayed relatively high richness estimates for both moderate- and high-uncertainty scenarios $(\sim 8-10$ and $6-8$, respectively), including the Aotea Basin, along the Norfolk Ridge, Challenger Plateau, and Campbell Plateau (Fig. 3B, C).

\section{Cetacean systematic conservation planning}

Spatial prioritization.-The top $30 \%$ of priority areas for cetacean diversity for the baseline scenario were broadly distributed across the study area (Fig. 4A). The highest priority areas identified for cetacean diversity (i.e., top $5 \%$ of areas, dark red; and top $10 \%$, light red in Fig. $4 \mathrm{~A}$ ) were located in both inshore and offshore areas. Inshore areas included most parts of the South Island (see Fig. 1 for place names, Fig. 4 A, iv) and the North Island (North Taranaki Bight and Hauraki Gulf; Fig. 4A, i). Similar to richness hotspots identified in the baseline scenario, offshore priority areas included the LauColville and Kermadec Ridges (Fig. 4A, iii), the areas on the Puysegur Trench (Fig. 4A, ii), and Bounty Trough extending onto the Campbell Plateau and the south Chatham Rise (Fig. 4A, iv). Areas with the next highest priority (top $20 \%$ of areas-orange in Fig. $4 \mathrm{~A}$ ) were predominately located along the Aotea Basin (Fig. 4A, i), along the western edge of the Campbell Plateau in the waters west of North East Island (Fig. 4A, ii), and the northern parts of the LauColville Ridge, Kermadec Ridge, and Kermadec Trench (Fig. 4A, iii), and the Bounty Trough (Fig. 4A, iv). 

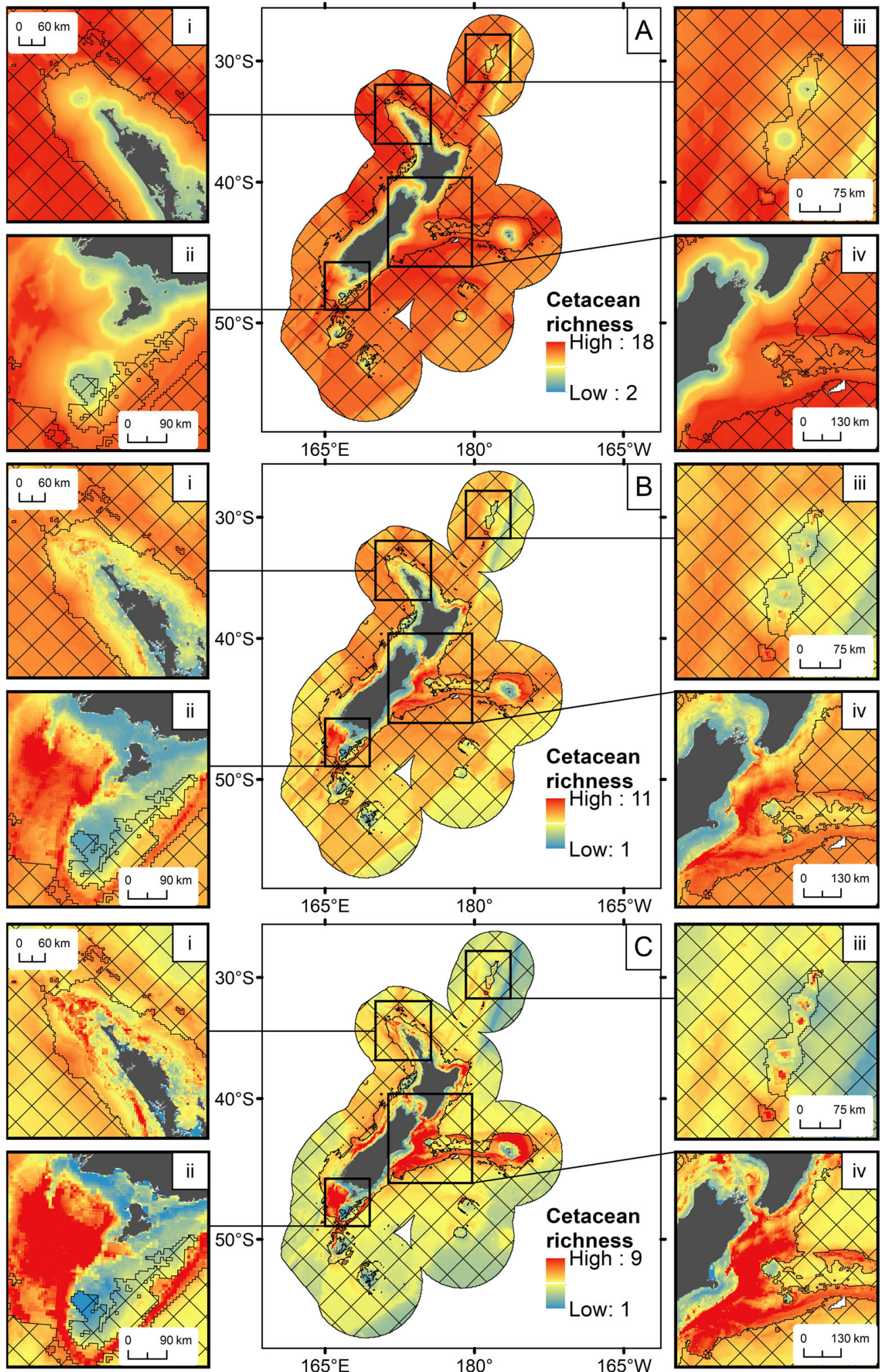

Fig. 3. Cetacean richness estimates in New Zealand derived from the addition of probability occurrences of 
(Fig. 3. Continued)

individual taxon distributions for (A) baseline scenario (modified from Stephenson et al. 2020a); (B) moderateuncertainty scenario; and (C) high-uncertainty scenario. Crisscross black lines indicate areas of low predicted environmental coverage depicting the lower confidence that can be placed in the predicted probability occurrence. Inset maps: (i) northern North Island including the North Cape and Hauraki Gulf; (ii) south of the South Island including Snares Island, Stewart Island, and parts of Fiordland Coast; (iii) Kermadec Islands, Lau-Colville Ridge, and Kermadec Ridge; (iv) south of the North Island including the South Taranaki Bight and Cook Strait and north of the South Island including the western Chatham Rise. Note the different scales for each inset map.

There were clear differences in the location of high-priority areas with the inclusion of uncertainty (Fig. 4B, C) compared with the baseline scenario (Fig. 4A). The high-priority areas very close to shore $(<10 \mathrm{~km})$ in most parts of the North and South Islands (i.e., top 5\% of areas, dark red in Fig. 4) were present across all scenarios. With increasing weighting of uncertainty, these areas extended further from shore (Fig. 4B, C). Some high-priority sites further offshore $(>50 \mathrm{~km})$ were identified in all scenarios, for example, parts of the Kermadec Ridge (Fig. 4A, B, C, iii), parts of the Puysegur Trench (Fig. 4A, B, C, ii), and the Bounty Trough and south Chatham Rise (Fig. 4A, B, C, iv). However, there was a large shift from high priority further offshore in areas with low environmental coverage in the baseline scenario (Fig. 4) to high-priority offshore sites. These shifts were within areas classified as having adequate environmental coverage (Fig. 4B), and these shifts increased for the high-uncertainty scenario (Fig. 4C). Areas identified as high-priority areas in the moderateand high-uncertainty scenarios included large parts of the North Cape (Fig. 4B, C, i), East Cape, South Taranaki Bight, Cook Strait (Fig. 4B, C), Kaikōura coast, and the western and eastern slopes of the Chatham Rise (Fig. 4B, C, iv). In both moderate- and high-uncertainty scenarios, some top priority areas were still selected in areas with low environmental coverage despite the increasing incorporation of uncertainty (e.g., parts of the Three Kings Ridge, Fig. 4B, C, i; Lau-Colville Ridge, Fig. 4B, C, iii) although these had reduced priority values compared to other areas with greater certainty in model predictions.

Taxon range.-For each priority level of the baseline scenario, at least some of each taxon distribution was represented; that is, the taxa with the lowest percentage distribution included in the top $5 \%$ of the baseline prioritization were Blainville's beaked whale and pygmy sperm whale with $3.6 \%$ of their distribution included in these areas (Table 2). Seventeen cetacean taxa were adequately represented in the top $5 \%$ of the area in the baseline scenario, that is, those taxa with $>5 \%$ of their distribution included in the top $5 \%$ of prioritized area (boldface italic numbers in Table 2). However, 13 of these taxa were those with low number of observations modeled using RES (considered less robust than the BRT models used for taxa with $>50$ sightings at sea). The number of adequately represented taxa increased with decreasing priority; that is, in the top $20 \%$ of baseline priority areas for cetacean diversity, 22 taxa out of 30 included in the analysis were adequately represented (boldface italic numbers in Table 2). However, 7 of the 15 taxa modeled with BRTs were not adequately represented at any priority level within the top 30\% of areas selected in the baseline scenario prioritization analysis (bottlenose dolphin, Bryde's whale, common dolphin, dusky dolphin, humpback whale, killer whale, and southern right whale; Table 2).

For each priority level of the moderate- and high-uncertainty scenarios, at least some of each taxon distribution was represented; for example, the taxon with the lowest percentage distribution included in the top $5 \%$ of the prioritization in both scenarios was the southern bottlenose whale with $2.7 \%$ of its distribution included in the top $5 \%$ of priority areas (Table 2). With increasing weighting of uncertainty, there was a shift from taxa with efficient solutions being predicted using RES models (i.e., offshore taxa, with fewer recorded sightings) to those taxa whose distributions were predicted using BRT models (Table 2). For example, in the high-uncertainty scenario, in the top $5 \%$ of priority areas, out of the 16 taxa that were adequately represented, 15 


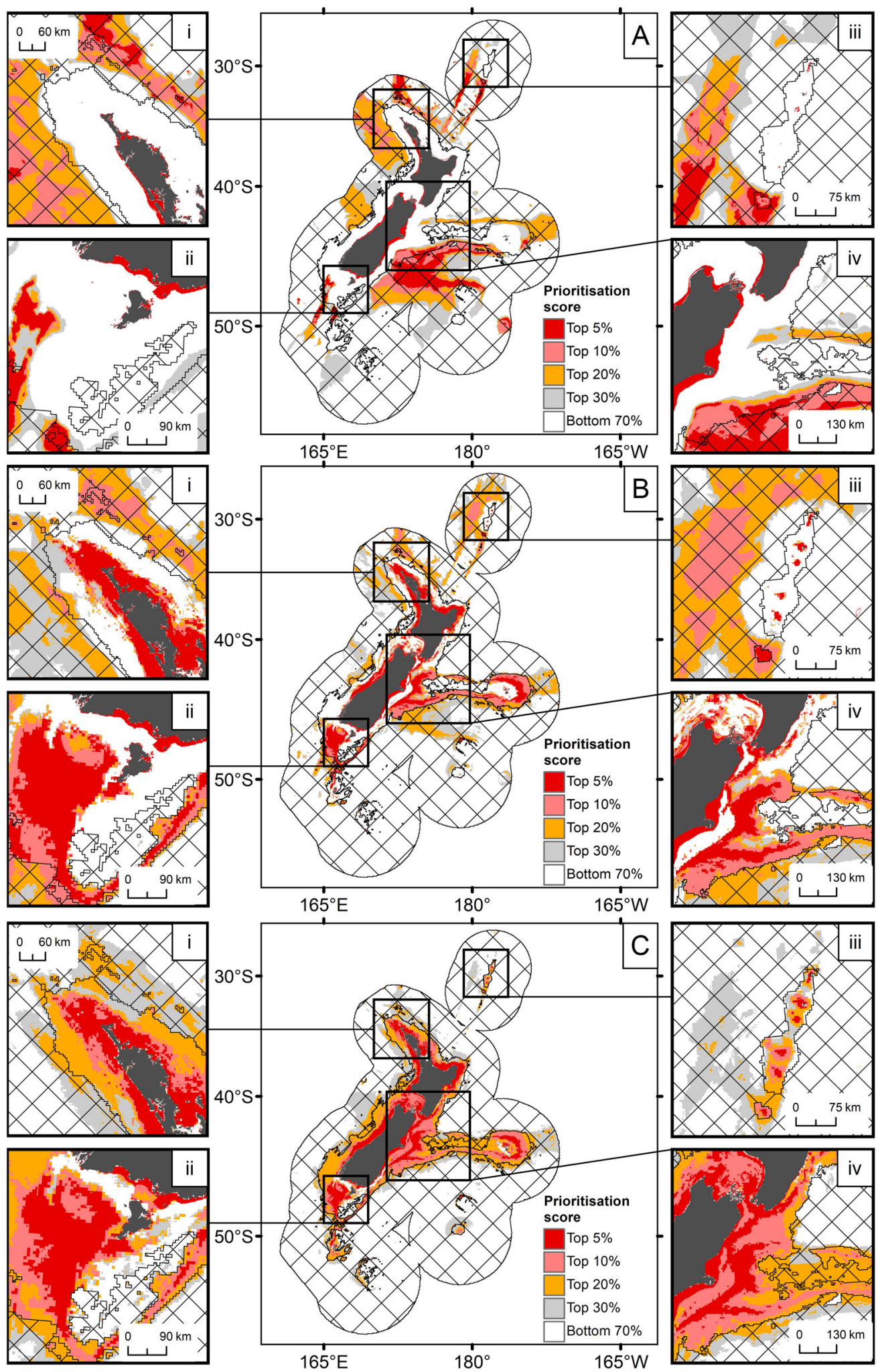

Fig. 4. Spatial diversity prioritization in New Zealand's EEZ (using the additive benefit function in Zonation 
(Fig. 4. Continued)

software) for the (A) baseline scenario; (B) moderate-uncertainty scenario; and (C) high-uncertainty scenario. Areas were identified from the highest to lowest priority in terms of conservation prioritization (top 5\%, 10\% $20 \%$, and $30 \%$ priority areas). Crisscross black lines indicate areas of low predicted environmental coverage depicting the lower confidence that can be placed in the predicted probability occurrence. Inset maps: (i) northern North Island including the Aotea Basin, North Cape, and Hauraki Gulf; (ii) south of the South Island including Snares Island, Stewart Island, and parts of Fiordland Coast; (iii) Kermadec Islands, Lau-Colville Ridge, and Kermadec Ridge; and (iv) east of the South Island including the Cook Strait, the western Chatham Rise, the Bounty Trough, and Bounty Plateau. Note the different scales for each inset map.

of these were taxa modeled using the more robust BRT models (taxa with $>50$ sightings at sea). The number of taxa whose proportion (\%) exceeded the prioritization percentage increased markedly with decreasing priority and with increasing weighting of uncertainty. For the high-uncertainty scenario, the top $30 \%$ of priority areas were deemed an efficient solution for all

Table 2. Proportion (\%) of cetacean taxon distribution within priority areas (top 5\%, 10\%, 20\%, and $30 \%$ priority areas) for each scenario: baseline (B); moderate uncertainty (MU); and high uncertainty (HU).

\begin{tabular}{|c|c|c|c|c|c|c|c|c|c|c|c|c|}
\hline \multirow[b]{2}{*}{ Taxa } & \multicolumn{3}{|c|}{ Top 5\% of area } & \multicolumn{3}{|c|}{ Top $10 \%$ of area } & \multicolumn{3}{|c|}{ Top $20 \%$ of area } & \multicolumn{3}{|c|}{ Top 30\% of area } \\
\hline & $B$ & MU & $\overline{\mathrm{HU}}$ & $\bar{B}$ & $\mathrm{MU}$ & $\overline{\mathrm{HU}}$ & 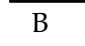 & $\mathrm{MU}$ & $\mathrm{HU}$ & B & $\mathrm{MU}$ & $\overline{\mathrm{HU}}$ \\
\hline Mean across all taxa & 8.8 & 8.7 & 11.2 & 14.6 & 14.3 & 18.1 & 26.0 & 25.2 & 29.3 & 37.0 & 35.9 & 39.8 \\
\hline Bottlenose dolphin & 4.1 & 5.7 & 10.7 & 8.4 & 10.7 & 17.1 & 17.5 & 21.1 & 26.6 & 27.3 & 31.3 & 35.9 \\
\hline Blue whale & 4.1 & 3.7 & 7.9 & 10.0 & 10.0 & 14.5 & 22.6 & 23.0 & 25.5 & 33.2 & 35.7 & 37.4 \\
\hline Bryde's whale & 4.8 & 12.0 & 20.5 & 9.3 & 17.4 & 28.1 & 18.5 & 27.5 & 37.9 & 27.9 & 36.8 & 46.4 \\
\hline Common dolphin & 4.8 & 14.6 & 27.4 & 9.4 & 21.5 & 39.0 & 18.3 & 32.1 & 49.7 & 26.9 & 41.9 & 57.7 \\
\hline Dusky dolphin & 4.5 & 8.3 & 13.7 & 8.8 & 14.0 & 24.0 & 16.7 & 21.8 & 37.8 & 25.5 & 29.2 & 46.1 \\
\hline Humpback whale & 5.0 & 6.3 & 11.5 & 9.5 & 11.5 & 18.7 & 19.0 & 21.9 & 29.1 & 28.9 & 31.8 & 38.2 \\
\hline Hector's dolphin & 100.0 & 100.0 & 99.9 & 100.0 & 100.0 & 100.0 & 100.0 & 100.0 & 100.0 & 100.0 & 100.0 & 100.0 \\
\hline Killer whale & 4.6 & 6.3 & 11.3 & 8.9 & 11.2 & 18.4 & 17.8 & 20.5 & 29.2 & 27.3 & 29.9 & 38.4 \\
\hline Māui dolphin & 14.8 & 20.7 & 31.1 & 18.8 & 24.9 & 35.4 & 26.8 & 33.5 & 41.9 & 35.4 & 41.7 & 48.9 \\
\hline Pilot whales & 4.5 & 4.6 & 7.4 & 10.0 & 9.6 & 14.5 & 20.2 & 19.2 & 26.4 & 30.5 & 29.0 & 36.6 \\
\hline Southern right whale & 5.9 & 7.3 & 11.9 & 9.9 & 11.8 & 19.9 & 18.1 & 19.2 & 31.2 & 27.5 & 26.5 & 40.0 \\
\hline Sperm whale & 4.9 & 4.4 & 6.9 & 10.6 & 9.9 & 13.3 & 21.8 & 20.8 & 24.5 & 32.9 & 31.6 & 35.2 \\
\hline Sei whale & 4.5 & 3.4 & 8.6 & 10.1 & 8.2 & 15.1 & 20.2 & 18.9 & 25.3 & 30.4 & 29.7 & 35.3 \\
\hline Fin whale & 4.5 & 4.9 & 10.5 & 10.2 & 10.3 & 18.0 & 20.4 & 21.1 & 28.7 & 30.7 & 31.9 & 38.9 \\
\hline Minke whale & 4.7 & 5.1 & 10.5 & 10.0 & 10.3 & 18.0 & 20.1 & 20.7 & 29.4 & 30.2 & 31.0 & 39.4 \\
\hline Andrew's beaked whale & 6.2 & 4.1 & 4.8 & 13.6 & 10.6 & 11.3 & 28.1 & 23.5 & 24.9 & 41.0 & 36.4 & 37.8 \\
\hline Arnoux's beaked whale & 5.7 & 3.8 & 4.5 & 12.5 & 9.7 & 10.5 & 26.2 & 21.6 & 23.2 & 39.1 & 33.5 & 35.3 \\
\hline Blainville's beaked whale & 3.6 & 3.3 & 4.4 & 10.3 & 11.0 & 10.2 & 27.6 & 27.2 & 24.7 & 40.4 & 43.0 & 40.1 \\
\hline Cuvier's beaked whale & 6.0 & 4.0 & 4.7 & 13.2 & 10.6 & 11.1 & 27.4 & 24.1 & 24.3 & 40.3 & 37.2 & 37.0 \\
\hline Dwarf minke whale & 5.5 & 3.8 & 4.7 & 12.2 & 9.8 & 10.9 & 25.4 & 22.1 & 23.3 & 38.2 & 34.2 & 35.2 \\
\hline False killer whale & 6.6 & 3.2 & 3.3 & 14.4 & 9.8 & 8.5 & 29.9 & 24.0 & 20.0 & 43.1 & 38.0 & 33.2 \\
\hline Gray's beaked whale & 5.7 & 3.8 & 4.5 & 12.5 & 9.7 & 10.5 & 26.2 & 21.6 & 23.2 & 39.1 & 33.5 & 35.3 \\
\hline Hourglass dolphin & 8.0 & 3.3 & 3.0 & 14.8 & 6.8 & 7.8 & 23.1 & 14.1 & 15.7 & 35.8 & 21.5 & 23.0 \\
\hline Pygmy sperm whale & 3.6 & 3.3 & 4.4 & 10.3 & 11.0 & 10.2 & 27.6 & 27.2 & 24.7 & 40.4 & 43.0 & 40.1 \\
\hline Risso's dolphin & 6.7 & 4.8 & 5.7 & 14.8 & 12.4 & 13.2 & 30.4 & 26.8 & 28.2 & 44.5 & 40.5 & 41.9 \\
\hline Southern bottlenose whale & 5.4 & 2.7 & 2.7 & 12.0 & 7.9 & 7.1 & 25.1 & 19.2 & 17.3 & 37.2 & 30.9 & 30.0 \\
\hline Shepherd's beaked whale & 6.2 & 3.0 & 3.1 & 13.8 & 9.0 & 8.1 & 28.7 & 21.6 & 20.1 & 42.1 & 34.3 & 31.8 \\
\hline Striped dolphin & 6.0 & 4.0 & 4.7 & 13.2 & 10.6 & 11.1 & 27.4 & 24.1 & 24.3 & 40.3 & 37.2 & 37.0 \\
\hline Spectacled porpoise & 7.9 & 4.2 & 4.4 & 14.7 & 8.2 & 10.6 & 22.9 & 15.5 & 20.2 & 35.8 & 22.8 & 27.7 \\
\hline Southern right whale dolphin & 5.7 & 3.8 & 4.5 & 12.5 & 9.7 & 10.5 & 26.2 & 21.6 & 23.2 & 39.1 & 33.5 & 35.3 \\
\hline
\end{tabular}

Notes: Adequate solutions for cetacean species are shown by boldface italic numbers (e.g., if more than $5 \%$ of a cetacean taxa's range is included in the top $5 \%$ of prioritized area, this would be considered an adequate solution). Cetacean taxon names are boldface for those cetacean taxa whose distributions were predicted using BRTs. 
but two taxa (hourglass dolphin, $23.0 \%$; spectacled porpoise, $27.7 \%$; Table 2 ).

\section{DISCUSSION}

Uncertainty is part of any decision-making process, and therefore, a transparent and robust method for dealing with gaps in information and data is required (Stelzenmüller et al. 2020). Knowledge gaps of marine species distributional data are common, yet spatial conservation management efforts must proceed while accounting for inherent uncertainty (Ansong et al. 2017). Here, we present an approach to estimate cetacean richness and spatial prioritization that explicitly accounts for varying levels of spatial uncertainty to provide a comprehensive overview of cetacean distribution in New Zealand waters. The use of uncertainty estimates allows the integration of distributional information from differing sources (different modeling methods with varying number of cetacean records) to be integrated in a robust and conservative way. This method is particularly important because it allows the integration of the limited spatial information available for rare taxa (RES models), which are seldom considered in a quantitative way for conservation planning.

\section{Cetacean hotspots}

Richness estimates and spatial prioritization methods provided complementary measures to identify diversity hotspots. Richness estimates highlight areas with high overlap of taxa distributions, whereas spatial prioritizations account for representativeness of cetacean taxa, thus highlighting the most efficient spatial arrangement to include the maximum ranges of all taxa. Despite some differences, both methods, across all uncertainty scenarios, highlighted several deep offshore waters as important for cetaceans. The congruence between methods and uncertainty scenarios provides evidence that these offshore areas are important for cetaceans. The complex topography in the New Zealand's EEZ spans subtropical to subantarctic waters and enables migratory or wide-ranging species to move across ocean basins (e.g., Thompson et al. 2016, Riekkola et al. 2018). Some species take advantage of prey (Torres et al. 2013) or may use ridges and seamounts or other cues to navigate
(Bouchet et al. 2015). This enables wider genetic connectivity of species seen in New Zealand waters, for example, Gray's beaked whales (Thompson et al. 2016), sperm whales (Alexander et al. 2016), and humpback whales (Riekkola et al. 2018) beyond the EEZ, highlighting the importance of global management approaches to such wide-ranging animals with few boundaries to dispersal. There is limited ability to corroborate the offshore hotspots identified in this study with independent data sets or anecdotal information although historical whaling data could be used (e.g., as in Torres et al. 2013, Carroll et al. 2014). However, the offshore locations identified here provide strong guidance for areas of importance requiring protection from anthropogenic impacts, or priority areas to undertake dedicated surveys to confirm species richness and ecosystem interactions.

Inshore areas generally had lower richness estimates; however, these areas were highlighted as important in all three uncertainty scenarios using the spatial prioritization method, and remain important for conservation for species with limited ranges, for example, Māui and Hector's dolphins and coastal bottlenose dolphins. With increased weighting of uncertainty, areas of moderate and high richness inshore (5-9) became more apparent because these areas were more certain and therefore retained their richness values. These areas included the following: Cook Strait, North Cape, Kermadec Islands, East Cape, South Taranaki Bight, and the west coast of South Island and northern parts of the North Island (Fig. 1). These inshore areas were also highlighted as important in the spatial prioritization analysis for scenarios with moderate- and high-uncertainty discounting. The high productivity and cetacean diversity within the waters of the South Taranaki Bight region ( 70-300 m) are assumed to be due to localized wind-driven upwelling system that leads to an abundance of krill (Bradford-Grieve et al. 1993). High densities of this prey resource make the region an important foraging ground for pygmy blue whales (Torres 2013, Barlow et al. 2020) and possibly other species of baleen whale such as sei whales and Bryde's whales observed in this broader region. There is some evidence that corroborates the other inshore locations highlighted as important in this study for several species 
(Childerhouse et al. 1995, Lusseau and Slooten 2002, Benoit-Bird et al. 2004, Barlow et al. 2018), but in most cases, there are no published summaries of species richness. This lack of information reflects the species-specific, localized studies that dominate cetacean research in New Zealand, which is largely focused on immediate conservation issues (Baker et al. 2019). Given the lack of information on cetacean hotspots in New Zealand, understanding the implications of incorporating uncertainty is particularly relevant.

\section{Incorporating uncertainty}

Environmental and ecosystem models provide a way for conservation practitioners to make management decisions for threatened species under significant uncertainty. While frameworks for formal decision-making have been applied in conservation contexts (Possingham 1997), uncertainty is rarely considered (Regan et al. 2002). Failure to acknowledge sources of uncertainty can lead to poor management decisions (Regan et al. 2005, Link et al. 2012). While uncertainty can readily be incorporated into single-species or single-sector models, for example, by quantifying the error around estimates, incorporation of uncertainty into multi-taxa models or for ecosystem-based management is more difficult. Here, we develop a methodological approach that explicitly incorporates two sources of uncertainty for 30 cetacean taxa. The two spatially explicit measures of uncertainty estimated here should not be considered in isolation and provide two complementary measures to be considered by managers. The environmental coverage provides an indication of which areas of the taxon's probability of occurrence are likely to have been extrapolated into unsampled space, that is, where there is limited information to validate the predicted relationships (Stephenson et al. 2020b). Associated uncertainty estimates of species' distribution provide an important indication of the variability in the modeling estimates (Leathwick et al. 2006). The cetacean distributions and the associated spatial uncertainty used here were estimated using occurrence records collected over the period of $40 \mathrm{yr}$ (Stephenson et al. $2020 b$ ). This broad temporal window means that the spatial predictions presented here should be interpreted as a temporally smoothed representation of cetacean hotspots. The uncertainty

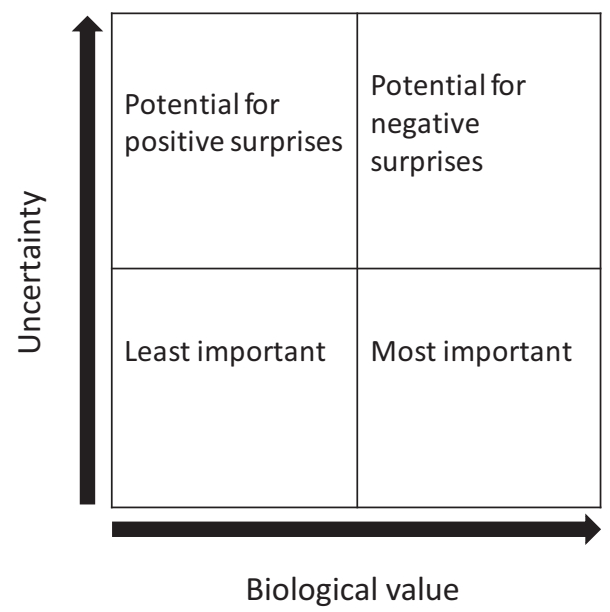

Fig. 5. Four broad outcomes for conservation based on biological quality and the certainty of that information (figure adapted from Moilanen et al. 2006a).

associated with any potential temporal changes in taxon distributions is not quantified here but may be important to consider in a management context (Azzellino et al. 2012, 2017).

The goal of uncertainty analysis in the context of conservation planning is to implement and evaluate trade-offs between biological quality and the certainty of that information (Moilanen et al. 2014). If uncertainty information is available, there are four broad considerations and outcomes for conservation (Moilanen and Wintle 2006, Moilanen et al. 2006b, Fig. 5). Areas with high biological value (e.g., high richness or core habitat of endangered species) with low uncertainty should be highlighted as most important (Fig. 5). Conversely, areas with low biological value and with low uncertainty should be highlighted as least important (Fig. 5). Areas with high biological value and with high uncertainty should be avoided for conservation - these are areas that may result in much lower conservation benefits than expected (Fig. 5). Finally, areas with low biological value and with high uncertainty have the potential for being higher value than initially estimated, although this potential benefit requires careful consideration (Fig. 5).

The adequate weighting of uncertainty remains a subjective decision. Here, we provide two examples to highlight differences and consistencies. For conservation planning, several analysis decisions would need to be made, including 
the appropriate levels of uncertainty to incorporate, whether all taxa are equally important in the analysis, and whether levels of uncertainty for all taxa are equal. Ideally, these somewhat subjective decisions would be made through a participatory process to ensure buy-in and acceptance of any subsequent policy decisions (Love 2017).

The aim of our moderate- and high-uncertainty scenarios was to highlight areas with high biological value and low uncertainty. Despite only having two uncertainty scenarios, we can draw conclusions on the importance of our areas for cetacean diversity. If an area is always highlighted as important irrespective of the weighting value of uncertainty, then we can be confident that the area is important for conservation (Moilanen et al. 2006b). For example, the offshore areas of the Lau-Colville and Kermadec Ridges, Macquarie Ridge, and along the western edge of the Campbell Plateau, the northern and western edges of the Bounty Trough, and the north and south of the Chatham Rise, and the areas surrounding the Chatham Islands were consistently highlighted in all our scenarios of richness and spatial prioritization analyses. If an area is highlighted as important with low weighting of uncertainty but not with high weighting of uncertainty, then we can conclude that the area contains high biological values, but these are uncertain, for example, many of the offshore areas within the environmental coverage. These areas can still be considered as important, but further investigation is required into the specific levels of uncertainty, the taxa driving these differences, and whether these taxa are considered more important than those in other areas. If the area is not highlighted as important with low weighting of uncertainty but is with high weighting of uncertainty, then we can conclude that the area may have moderate levels of importance with high certainty. For example, inshore areas in the Cook Strait, North Cape, Kermadec Islands, East Cape, South Taranaki Bight, and the west coast of South Island and northern parts of the North Island had moderate levels of richness (5-8) but low uncertainty. These areas became more clearly highlighted as important with increasing weighting of uncertainty.

\section{Spatial management of cetaceans}

New information on spatial hotspots in cetacean diversity can provide environmental managers with opportunities to mitigate a range of threats to these taxa. While new information on the distribution of cetacean diversity across the whole EEZ may be considered the best available information, it is still important to acknowledge that much of this habitat, both inshore and offshore, remains unsampled. Thus, decision-makers should carefully consider this uncertainty when considering management actions, such as the approach presented here. Helpfully, the uncertainty measures generated in this study, particularly coverage of the environmental space, allow for stakeholderfriendly representation of this uncertainty as part of a participatory decision-making process (Stelzenmüller et al. 2020).

Spatial models that depict probability of species presence are useful to establish important locations for cetacean diversity (Kaschner et al. 2011, Tobeña et al. 2016). However, the species often have marked variation in abundance as a function of variable residency patterns, migratory patterns, and local/regional endemism. Modeling the relative abundance or density of species would allow the incorporation of such effects into spatial prioritization-and would likely improve the effectiveness of any spatial management (Williams et al. 2014, Johnston 2015). Williams et al. (2014) found high-density areas of most species was inversely related to richness-thus, spatial management based on richness alone would not select areas important for certain species (Albouy et al. 2017). The decision whether to favor diversity or density for individual taxa is a consideration best deliberated during stakeholder participatory processes in conservation planning. However, data to calculate abundance/density are not currently available for many cetacean species, including in New Zealand due to a lack of targeted surveys (but see some taxa modeled in Stephenson et al. 2020a). Targeted surveys that fill data gaps should be prioritized with future research.

The hotspots in cetacean diversity identified in this study can enable spatially explicit management of threats to these taxa, some of which would otherwise be afforded no management efforts due to knowledge gaps. Rather than discounting taxa with few data points from our effort 
to describe cetacean diversity, we incorporated all relevant data and accounted for the associated uncertainty. Hence, our results allow managers to scale management decisions along spectrums of diversity and uncertainty simultaneously based on species' importance and/or levels of acceptable risk (e.g., as discussed in Incorporating uncertainty). Such spatially explicit results can be considered alongside threats such as fishing effort and shipping traffic to quantify risk, direct research and monitoring efforts, and ultimately apply effective management schemes. Cetaceans may be impacted by different anthropogenic drivers; for example, climate change is likely to impact many of New Zealand's cetacean species (Learmonth et al. 2006, Simmonds and Isaac 2007). The large EEZ may provide space for the deep-water cetaceans that make up a substantial part of New Zealand's cetacean taxa to adapt to changing ocean conditions (e.g., through foraging plasticity as observed in the Gulf of St. Lawrence, Canada, by Ramp et al. 2015). Greater knowledge on hotspots for deep-diving species may allow the identification of climate change refugia so that management can reduce potential threats in these areas. Shifts in prey availability associated with oceanographic phenomena (Scales et al. 2017) or fishing pressures (Bearzi et al. 2006) may drive variation in distribution and habitat use over different spatial and temporal scales. In addition, pressure from tourism, recreational vessels, shipping, and industrial development can drive cetaceans away from critical habitat (Allen and Read 2000, Azzellino et al. 2017, Derville et al. 2019). Thus, understanding the functional relationships between oceanography, prey, and cetacean behavior that drive predator distribution patterns (e.g., Guerra et al. 2017, Izadi et al. 2018, Barlow et al. 2020) will likely improve the potential for management policies to effectively adapt under a changing climate. For the non-migratory, nearshore species, understanding behavioral plasticity and prey preferences is important when considering the effects of climate change in addition to other anthropogenic threats.

\section{ACKNOWLEDGMENTS}

This work was funded by the NIWA Fisheries Programme (Project FIAR2001), the Sustainable Seas National Science Challenge Phase II projects "3.2.
Communicating Risk and Uncertainty to Aid Decision Making" and "1.2. Tools for Incorporating Ecological Responses to Cumulative Effects into Management Actions," based on modeling carried out under contract PRO201401 from the Ministry for Primary Industries. We thank J Leathwick for discussing and providing useful insights on modeling species distributions, richness, and conservation planning analyses. We thank the New Zealand Department of Conservation for providing the cetacean sighting records used to build individual species distribution models. We acknowledge B Sharp and Fisheries New Zealand for providing advice and for support in earlier work on which we built. The findings and conclusions in this paper are those of the authors and do not necessarily represent the views of the National Marine Fisheries Service, NOAA. Mention of trade names and commercial firms does not imply endorsement by the National Marine Fisheries Service, NOAA.

\section{Literature Cited}

Abrahms, B., H. Welch, S. Brodie, M. G. Jacox, E. A. Becker, S. J. Bograd, L. M. Irvine, D. M. Palacios, B. R. Mate, and E. L. Hazen. 2019. Dynamic ensemble models to predict distributions and anthropogenic risk exposure for highly mobile species. Diversity and Distributions 25:1182-1193.

Albouy, C., V. Delattre, G. Donati, T. L. Frölicher, S. Albouy-Boyer, M. Rufino, L. Pellissier, D. Mouillot, and F. Leprieur. 2020. Global vulnerability of marine mammals to global warming. Scientific Reports 10:1-12.

Albouy, C., V. L. Delattre, B. Mérigot, C. N. Meynard, and F. Leprieur. 2017. Multifaceted biodiversity hotspots of marine mammals for conservation priorities. Diversity and Distributions 23:615-626.

Alexander, A., D. Steel, K. Hoekzema, S. L. Mesnick, D. Engelhaupt, I. Kerr, R. Payne, and C. S. Baker. 2016. What influences the worldwide genetic structure of sperm whales (Physeter macrocephalus)? Molecular Ecology 25:2754-2772.

Allen, M. C., and A. J. Read. 2000. Habitat selection of foraging bottlenose dolphins in relation to boat density near clearwater, Florida. Marine Mammal Science 16:815-824.

Ansong, J., E. Gissi, and H. Calado. 2017. An approach to ecosystem-based management in maritime spatial planning process. Ocean \& Coastal Management 141:65-81.

Azzellino, A., S. Airoldi, C. Lanfredi, M. Podestà, and M. Zanardelli. 2017. Cetacean response to environmental and anthropogenic drivers of change: results of a 25-year distribution study in the northwestern 
Mediterranean Sea. Deep Sea Research Part II: Topical studies in Oceanography 146:104-117.

Azzellino, A., S. Panigada, C. Lanfredi, M. Zanardelli, S. Airoldi, and G. Notarbartolo di Sciara. 2012. Predictive habitat models for managing marine areas: spatial and temporal distribution of marine mammals within the Pelagos Sanctuary (Northwestern Mediterranean sea). Ocean \& Coastal Management 67:63-74.

Baker, C. S., L. Boren, S. Childerhouse, R. Constantine, A. van Helden, D. Lundquist, W. Rayment, and J. R. Rolfe. 2019. Conservation status of New Zealand marine mammals, 2019. Department of Conservation, New Zealand Threat Classification Series 29, Wellington, New Zealand.

Barlow, D. R., et al. 2018. Documentation of a New Zealand blue whale population based on multiple lines of evidence. Endangered Species Research $36: 27-40$.

Barlow, D. R., K. S. Bernard, P. Escobar-Flores, D. M. Palacios, and L. G. Torres. 2020. Links in the trophic chain: modeling functional relationships between in situ oceanography, krill, and blue whale distribution under different oceanographic regimes. Marine Ecology Progress Series 642:207-225.

Beale, C. M., and J. J. Lennon. 2012. Incorporating uncertainty in predictive species distribution modelling. Philosophical Transactions of the Royal Society B: Biological Sciences 367:247-258.

Bean, W. T., R. Stafford, and J. S. Brashares. 2012. The effects of small sample size and sample bias on threshold selection and accuracy assessment of species distribution models. Ecography 35:250-258.

Bearzi, G., E. Politi, S. Agazzi, and A. Azzellino. 2006. Prey depletion caused by overfishing and the decline of marine megafauna in eastern Ionian Sea coastal waters (central Mediterranean). Biological Conservation 127:373-382.

Benoit-Bird, K. J., B. Würsig, and C. J. Mfadden. 2004. Dusky dolphin (Lagenorhynchus obscurus) foraging in two different habitats: active acoustic detection of dolphins and their prey. Marine Mammal Science 20:215-231.

Bouchet, P. J., J. J. Meeuwig, C. P. Salgado Kent, T. B. Letessier, and C. K. Jenner. 2015. Topographic determinants of mobile vertebrate predator hotspots: current knowledge and future directions. Biological Reviews 90:699-728.

Bradford-Grieve, J. M., R. C. Murdoch, and B. E. Chapman. 1993. Composition of macrozooplankton assemblages associated with the formation and decay of pulses within an upwelling plume in greater Cook Strait, New Zealand. New Zealand Journal of Marine and Freshwater Research 27:122.
Bradford-Grieve, J., K. Probert, K. Lewis, P. Sutton, J. Zeldis, and A. Orpin. 2006. New Zealand shelf region. Harvard University Press, Cambridge, Massachusetts, USA.

Calabrese, J. M., G. Certain, C. Kraan, and C. F. Dormann. 2014. Stacking species distribution models and adjusting bias by linking them to macroecological models. Global Ecology and Biogeography 23:99-112.

Carroll, E. L., J. A. Jackson, D. Paton, and T. D. Smith. 2014. Two intense decades of 19th century whaling precipitated rapid decline of right whales around New Zealand and East Australia. PLOS ONE 9:e93789.

Childerhouse, S. J., S. M. Dawson, and E. Slooten. 1995. Abundance and seasonal residence of sperm whales at Kaikoura, New Zealand. Canadian Journal of Zoology 73:723-731.

Clapham, P., and C. Baker. 2018. Whaling, modern. Pages 1070-1074 in B. Würsig, J. Thewissen, K. Kovacs, and editors. Encyclopedia of marine mammals. Third edition. Academic Press, San Francisco, California, USA.

Costello, M. J. 2019. Unhelpful inflation of threatened species. Science 365:332-333.

Davidson, A. D., A. G. Boyer, H. Kim, S. PompaMansilla, M. J. Hamilton, D. P. Costa, G. Ceballos, and J. H. Brown. 2012. Drivers and hotspots of extinction risk in marine mammals. Proceedings of the National Academy of Sciences of the United States of America 109:3395-3400.

Derville, S., L. G. Torres, R. Dodémont, V. Perard, and C. Garrigue. 2019. From land and sea, long-term data reveal persistent humpback whale (Megaptera novaeangliae) breeding habitat in New Caledonia. Aquatic Conservation: Marine and Freshwater Ecosystems 29:1697-1711.

Elith, J., et al. 2006. Novel methods improve prediction of species' distributions from occurrence data. Ecography 29:129-151.

Elith, J., M. Kearney, and S. Phillips. 2010. The art of modelling range-shifting species. Methods in Ecology and Evolution 1:330-342.

Ferrer-Sánchez, Y., and R. Rodríguez-Estrella. 2016. How rare species conservation management can be strengthened with the use of ecological niche modelling: the case for endangered endemic Gundlach's Hawk and Cuban Black-Hawk. Global Ecology and Conservation 5:88-99.

Ferrier, S., and A. Guisan. 2006. Spatial modelling of biodiversity at the community level. Journal of Applied Ecology 43:393-404.

Friday, N. A., A. N. Zerbini, J. M. Waite, S. E. Moore, and P. J. Clapham. 2013. Cetacean distribution and abundance in relation to oceanographic domains on the eastern Bering Sea shelf, June and July of 
2002, 2008, and 2010. Deep Sea Research Part II: Topical studies in Oceanography 94:244-256.

Granger, V., N. Bez, J. M. Fromentin, C. Meynard, A. Jadaud, and B. Merigot. 2015. Mapping diversity indices: not a trivial issue. Methods in Ecology and Evolution 6:688-696.

Guerra, M., L. Hickmott, J. van der Hoop, W. Rayment, E. Leunissen, E. Slooten, and M. Moore. 2017. Diverse foraging strategies by a marine top predator: Sperm whales exploit pelagic and demersal habitats in the Kaikōura submarine canyon. Deep Sea Research Part I: Oceanographic Research Papers 128:98-108.

Guisan, A., and W. Thuiller. 2005. Predicting species distribution: offering more than simple habitat models. Ecology Letters 8:993-1009.

Hammerschlag, N., O. J. Schmitz, A. S. Flecker, K. D. Lafferty, A. Sih, T. B. Atwood, A. J. Gallagher, D. J. Irschick, R. Skubel, and S. J. Cooke. 2019. Ecosystem function and services of aquatic predators in the Anthropocene. Trends in Ecology \& Evolution 34:369-383.

Hillman, J. R., F. Stephenson, S. F. Thrush, and C. J. Lundquist. 2020. Investigating changes in estuarine ecosystem functioning under future scenarios. Ecological Applications 30:e02090.

Hoffmann, M., et al. 2010. The impact of conservation on the status of the world's vertebrates. Science 330:1503-1509.

Hückstädt, L. A., A. Piñones, D. M. Palacios, B. I. McDonald, M. S. Dinniman, E. E. Hofmann, J. M. Burns, D. E. Crocker, and D. P. Costa. 2020. Projected shifts in the foraging habitat of crabeater seals along the Antarctic Peninsula. Nature Climate Change 10:1-6.

IUCN. 2001. IUCN Red List categories and criteria. IUCN Species Survival Commission, Gland, Switzerland and Cambridge, UK.

IUCN. 2015. The IUCN red list of threatened species. International Union for Conservation of Nature and Natural Resources. Online at: http://www.iuc nredlist.org/

Izadi, S., M. Johnson, N. A. de Soto, and R. Constantine. 2018. Night-life of Bryde's whales: ecological implications of resting in a baleen whale. Behavioral Ecology and Sociobiology 72:78.

Jepson, P. D., et al. 2016. PCB pollution continues to impact populations of orcas and other dolphins in European waters. Scientific Reports 6:18573.

Johnston, A., D. Fink, M. D. Reynolds, W. M. Hochachka, B. L. Sullivan, N. E. Bruns, E. Hallstein, M. S. Merrifield, S. Matsumoto, and S. Kelling. 2015. Abundance models improve spatial and temporal prioritization of conservation resources. Ecological Applications 25:1749-1756.
Kaschner, K., D. P. Tittensor, J. Ready, T. Gerrodette, and B. Worm. 2011. Current and future patterns of global marine mammal biodiversity. PLOS ONE 6: e19653.

Kaschner, K., R. Watson, A. W. Trites, and D. Pauly. 2006. Mapping world-wide distributions of marine mammal species using a relative environmental suitability (RES) model. Marine Ecology Progress Series 316:285-310.

Kesner-Reyes, K., K. Kaschner, S. Kullander, C. Garilao, J. Barile, and R. Froese. 2016. AquaMaps: algorithm and data sources for aquatic organisms. www.fishbase.org, version (04/2012).

Laidre, K. L., S. Atkinson, E. V. Regehr, H. L. Stern, E. W. Born, Ø. Wiig, N. J. Lunn, and M. Dyck. 2020. Interrelated ecological impacts of climate change on an apex predator. Ecological Applications 30: $\mathrm{e} 02071$.

Learmonth, J. A., C. D. MacLeod, M. B. Santos, G. J. Pierce, H. Crick, and R. A. Robinson. 2006. Potential effects of climate change on marine mammals. Oceanography and Marine Biology 44:431.

Leathwick, J., J. Elith, M. Francis, T. Hastie, and P. Taylor. 2006. Variation in demersal fish species richness in the oceans surrounding New Zealand: an analysis using boosted regression trees. Marine Ecology Progress Series 321:267-281.

Link, J. S., T. Ihde, C. Harvey, S. K. Gaichas, J. Field, J. Brodziak, H. Townsend, and R. Peterman. 2012. Dealing with uncertainty in ecosystem models: the paradox of use for living marine resource management. Progress in Oceanography 102:102-114.

Love, T. 2017. The Kermadecs conundrum: marine protected areas and democratic process. Policy Quarterly 13:17-22.

Lusseau, D., and E. Slooten. 2002. Cetacean sightings off the Fiordland coastline. Science for Conservation 187:1-42.

Marchese, C. 2015. Biodiversity hotspots: a shortcut for a more complicated concept. Global Ecology and Conservation 3:297-309.

Mason, N., M. Ward, J. E. M. Watson, O. Venter, and R. K. Runting. 2020. Global opportunities and challenges for transboundary conservation. Nature Ecology and Evolution 4:694-701.

Meyer-Gutbrod, E. L., and C. H. Greene. 2018. Uncertain recovery of the North Atlantic right whale in a changing ocean. Global Change Biology 24:455464.

Moilanen, A. 2007. Landscape zonation, benefit functions and target-based planning: unifying reserve selection strategies. Biological Conservation 134: 571-579.

Moilanen, A., H. Kujala, and H. P. Possingham. 2009. The Zonation framework and software for 
conservation prioritization. Oxford University Press, Oxford, UK.

Moilanen, A., J. R. Leathwick, and J. M. Quinn. 2011. Spatial prioritization of conservation management. Conservation Letters 4:383-393.

Moilanen, A., F. M. Pouzols, L. Meller, V. Veach, A. Arponen, J. Leppänen, and H. Kujala. 2014. Zonation-Spatial conservation planning methods and software. Version 4. User Manual 290. https:// www2.helsinki.fi/en/researchgroups/digital-geogra phy-lab/software-developed-in-cbig

Moilanen, A., M. C. Runge, J. Elith, A. Tyre, Y. Carmel, E. Fegraus, B. A. Wintle, M. Burgman, and Y. BenHaim. 2006a. Planning for robust reserve networks using uncertainty analysis. Ecological Modelling 199:115-124.

Moilanen, A., B. A. Wintle, J. Elith, and M. Burgman. 2006b. Uncertainty analysis for regional-scale reserve selection. Conservation Biology 20:1688-1697.

Moilanen, A., and B. A. Wintle. 2006. Uncertainty analysis favours selection of spatially aggregated reserve networks. Biological Conservation 129:427434.

Mouillot, D., et al. 2013. Rare species support vulnerable functions in high-diversity ecosystems. PLOS Biology 11:e1001569.

Myers, N. 1988. Threatened biotas:" hot spots" in tropical forests. The Environmentalist 8:187-208.

Myers, N., R. A. Mittermeier, C. G. Mittermeier, G. A. Da Fonseca, and J. Kent. 2000. Biodiversity hotspots for conservation priorities. Nature 403:853.

Norman, M. 2003. Biodiversity hotspots revisited. BioScience 53:916-917.

Orme, C. D. L., et al. 2005. Global hotspots of species richness are not congruent with endemism or threat. Nature 436:1016-1019.

Pershing, A. J., and K. Stamieszkin. 2020. The North Atlantic ecosystem, from plankton to whales. Annual Review of Marine Science 12:339-359.

Possingham, H. P. 1997. State-dependent decision analysis for conservation biology. Pages 298-304 in S. Pickett, R. S. Ostfeld, M. Shachak, and G. Likens, editors. The ecological basis of conservation: heterogeneity, ecosystems, and biodiversity. Springer, New York, New York, USA.

Purvis, A., S. H. Butchart, E. S. Brondízio, J. Settele, and S. Díaz. 2019. No inflation of threatened species. Science 365:767.

Ramírez, F., I. Afán, L. S. Davis, and A. Chiaradia. 2017. Climate impacts on global hot spots of marine biodiversity. Science Advances 3:e1601198.

Ramp, C., J. Delarue, P. J. Palsbøll, R. Sears, and P. S. Hammond. 2015. Adapting to a warmer ocean Seasonal shift of baleen whale movements over three decades. PLOS ONE 10:e0121374.
Reeves, R. R. 2018. Hunting. Pages 492-496 in B. Würsig, J. Thewissen, and K. Kovacs, editors. Encyclopedia of marine mammals. Third edition. Academic Press, San Francisco, California, USA.

Regan, H. M., Y. Ben-Haim, B. Langford, W. G. Wilson, P. Lundberg, S. J. Andelman, and M. A. Burgman. 2005. Robust decision-making under severe uncertainty for conservation management. Ecological Applications 15:1471-1477.

Regan, H. M., M. Colyvan, and M. A. Burgman. 2002. A taxonomy and treatment of uncertainty for ecology and conservation biology. Ecological Applications 12:618-628.

Riekkola, L., et al. 2018. Application of a multidisciplinary approach to reveal population structure and Southern Ocean feeding grounds of humpback whales. Ecological Indicators 89:455465.

Rowden, A. A., F. Stephenson, M. R. Clark, O. F. Anderson, J. M. Guinotte, S. J. Baird, M.-J. Roux, S. Wadhwa, M. Cryer, and C. J. Lundquist. 2019. Examining the utility of a decision-support tool to develop spatial management options for the protection of vulnerable marine ecosystems on the high seas around New Zealand. Ocean \& Coastal Management 170:1-16.

Scales, K. L., G. S. Schorr, E. L. Hazen, S. J. Bograd, P. I. Miller, R. D. Andrews, A. N. Zerbini, and E. A. Falcone. 2017. Should I stay or should I go? Modelling year-round habitat suitability and drivers of residency for fin whales in the California Current. Diversity and Distributions 23:1204-1215.

Schipper, J., et al. 2008. The status of the world's land and marine mammals: diversity, threat, and knowledge. Science 322:225-230.

Simmonds, M. P., and S. J. Isaac. 2007. The impacts of climate change on marine mammals: early signs of significant problems. Oryx 41:19-26.

Smith, A. N., C. Duffy, J. Anthony, and J. R. Leathwick. 2013. Predicting the distribution and relative abundance of fishes on shallow subtidal reefs around New Zealand. Department of Conservation, Wellington, New Zealand.

Stelzenmüller, V., et al. 2020. Operationalizing riskbased cumulative effect assessments in the marine environment. Science of the Total Environment 724:138118.

Stephenson, F., K. Goetz, T. Mouton, F. Beets, S. Hailes, J. Roberts, M. Pinkerton, and A. MacDiarmid. 2020a. Spatial distribution modelling of New Zealand cetacean species. Report No. 240. New Zealand Aquatic Environment and Biodiversity, Wellington, New Zealand.

Stephenson, F., K. Goetz, B. R. Sharp, T. L. Mouton, F. L. Beets, J. Roberts, A. B. MacDiarmid, R. 
Constantine, and C. J. Lundquist. 2020b. Modelling the spatial distribution of cetaceans in New Zealand waters. Diversity and Distributions 26:495516.

Stephenson, F., J. R. Leathwick, S. W. Geange, R. H. Bulmer, J. E. Hewitt, O. F. Anderson, A. A. Rowden, and C. J. Lundquist. 2018. Using Gradient Forests to summarize patterns in species turnover across large spatial scales and inform conservation planning. Diversity and Distributions 24:1641-1656.

Stockwell, D. R., and A. T. Peterson. 2002. Effects of sample size on accuracy of species distribution models. Ecological Modelling 148:1-13.

Szpak, P., M. Buckley, C. M. Darwent, and M. P. Richards. 2018. Long-term ecological changes in marine mammals driven by recent warming in northwestern Alaska. Global Change Biology 24:490-503.

Thompson, K. F., S. Patel, C. S. Baker, R. Constantine, and C. D. Millar. 2016. Bucking the trend: Genetic analysis reveals high diversity, large population size and low differentiation in a deep ocean cetacean. Heredity 116:277-285.

Tobeña, M., R. Prieto, M. Machete, and M. A. Silva. 2016. Modeling the potential distribution and richness of cetaceans in the Azores from fisheries observer program data. Frontiers in Marine Science 3. https://doi.org/10.3389/fmars.2016.00202

Torres, L. 2013. Evidence for an unrecognised blue whale foraging ground in New Zealand. New Zealand Journal of Marine and Freshwater Research 47:235-248.
Torres, L. G., T. D. Smith, P. Sutton, A. MacDiarmid, J. Bannister, and T. Miyashita. 2013. From exploitation to conservation: Habitat models using whaling data predict distribution patterns and threat exposure of an endangered whale. Diversity and Distributions 19:1138-1152.

Veach, V., E. Di Minin, F. M. Pouzols, and A. Moilanen. 2017. Species richness as criterion for global conservation area placement leads to large losses in coverage of biodiversity. Diversity and Distributions 23:715-726.

Virtanen, E. A., M. Viitasalo, J. Lappalainen, and A. Moilanen. 2018. Evaluation, gap analysis, and potential expansion of the Finnish Marine Protected Area Network. Frontiers in Marine Science 5. https://doi.org/10.3389/fmars.2018.00402

Williams, R., J. Grand, S. K. Hooker, S. T. Buckland, R. R. Reeves, L. Rojas-Bracho, D. Sandilands, and K. Kaschner. 2014. Prioritizing global marine mammal habitats using density maps in place of range maps. Ecography 37:212-220.

Wisz, M. S., R. J. Hijmans, J. Li, A. T. Peterson, C. H. Graham, A. Guisan, and NCEAS Predicting Species Distributions Working Group. 2008. Effects of sample size on the performance of species distribution models. Diversity and Distributions 14:763773.

Woinarski, J., P. Whitehead, D. Bowman, and J. Russell-Smith. 1992. Conservation of mobile species in a variable environment: the problem of reserve design in the Northern Territory, Australia. Global Ecology and Biogeography Letters 2:1-10.

\section{SUPPORTING INFORMATION}

Additional Supporting Information may be found online at: http://onlinelibrary.wiley.com/doi/10.1002/ecs2. 3633/full 